\title{
Religión y moral
}

\author{
JUAN MARTIN VELASCO \\ Universidad Pontificia de Salamanca
}

Religion y moralidad son hechos estrechamente relacionados a lo largo de la historia. Esta relación da lugar a contenidos éticos convergentes en la mayor parte de las tradiciones religiosas. Existen sin embargo tensiones entre la moral y la religión que culminan en la ruptura operada por los movimientos «ilustrados». Operada esta ruptura, religión y moralidad aparecen como distintas formas de relación con el absoluto, llamadas a dialogar, desde la base de la ética civil de las sociedades pluralistas, para buscar soluciones a los problemas de la humanidad actual.

No es necesario estar familiarizado con los innumerables tratamientos que ha recibido a lo largo de la historia del pensamiento humano el problema a que se refiere nuestro título para hacerse cargo de su complejidad y la dificultad que encierra. Para tratarlo de forma adecuada sería necesario, por una parte, explicar el contenido de los términos "religion" y «moral» y exponer, por tanto, los dos mundos a los que remiten y, por otra, desentrañar la compleja relación que mantienen. Nuestra intención es examinar especialmente la segunda cuestión y abordar la primera sólo en la medida en que es indispensable para la segunda y en función de ésta.

"Moral" o «ética», porque vamos a utilizar los dos términos con idéntico significado, ${ }^{1}$ remiten a una dimensión de la persona. Aquella que se manifiesta en el hecho de que el hombre, al ejercitar su existencia, no se limita a desarrollar las facultades de que está dotado, a realizar sus posibilidades, a satisfacer sus deseos y a colmar sus necesidades, sino que se ve interiormente obligado a tener en cuenta un ser ideal, un bien, que juzga sus acciones, reclama el asentimiento de su libertad y se hace presente a su conciencia como valor que dignifica su vida. Este bien, que orienta el conjunto de la existencia, se desgrana para él en un sistema de bienes que rigen los diferentes sectores de su vida. Su presencia se manifiesta en la pregunta ¿qué debo hacer? que acompaña a todo lo que hace. La relación del hombre con esa presencia confiere una nueva calidad a sus actos que, más allá de lo agradable o desagradable, de lo útil o inútil, se expresa en términos de debido o indebido, justo o injusto, y se difunde sobre la totalidad de la persona haciéndola percibirse como buena o mala. La dimensión moral de la persona y su ejercicio han originado a lo largo de su historia un "hecho moral", que forma parte del hecho huma- 
no y como éste aparece en formas variadas de acuerdo con las diferentes historias y culturas.

Con el término "religión» designamos una nueva dimensión de la persona gracias a la cual el hombre reconoce en una actitud fundamental de reconocimiento y aceptación una realidad sobrehumana como origen y como destino último y salvación de su vida. En la religión responde el hombre a la pregunta: "¿qué sentido tiene mi vida?», "¿qué me cabe esperar?" y gracias a ella incluye en un horizonte global de sentido y de valor el discurrir completo de la vida y la totalidad de su ser personal. La actitud religiosa fundamental es "vivenciada" por el sujeto en experiencias especificas que ponen en juego todas las facetas del ser humano: espacio-temporal, racional, activa, emotiva y dan lugar a una forma de vida especial, la vida religiosa. De esta forma la religión origina también un hecho religioso que forma parte del complejo hecho humano y que como la propia historia humana aparece diversificado en las diferentes religiones de la historia. Desde esta somera explicación de los términos, se comprende que el problema de la relación entre religión y moral puede plantearse de formas muy diferentes según el nivel en que nos situemos al hacerlo.

Cabe, por ejemplo, preguntarse por las conexiones del hecho religioso y el hecho moral tal como aparece en la historia: ¿es posible establecer la precedencia del uno sobre el otro? Pero cabe también indagar las relaciones de las dimensiones y actitudes profundas de las que esos hechos proceden. ¿Coinciden en lo esencial o son fenomenológicamente diferentes? ¿Es la actitud religiosa fundamento de la obligatoriedad que comporta la moral? ¿Cómo se relaciona esa obligatoriedad con la realidad sobrehumana reconocida por el hombre religioso como Dios, lo divino u otro término homólogo? ¿Es al contrario la conciencia moral criterio de autenticidad para la relación religiosa? El tratamiento de estas últimas cuestiones de carácter teórico, que son sin duda las decisivas, podrá ser planteada con mayores garantías tras un contacto prolongado con los datos objetivos que componen el hecho moral y el hecho religioso.

Por eso comenzaremos nuestra reflexión estudiando la relación entre hecho religioso y vida moral a partir de una lectura, necesariamente selectiva, de la historia.

\section{Religion y vida moral en la historia religiosa de la humanidad}

El primer hecho que nos impone la historia de las religiones como una verdadera evidencia es la presencia en todas las religiones de una preocupación por la moralidad de sus adeptos y de unas orientaciones para su desarrollo. Todas las religiones han segregado una moral. "No existe religión alguna, afirma $M$. Müller, $o$, al menos yo no conozco ninguna que no diga: "haz el bien; evita el mal". Ninguna que no contenga lo que Rabbí 
Hillel llamaba la quintaesencia de todas las religiones: "sé bueno, hijo mío"».2

A partir de esta constatación de la presencia de la moral en el interior de la religión, las relaciones entre ambas aparecen en numerosos aspectos. El más importante se refiere a los distintos modelos de moralidad que corresponden a los diferentes tipos de religion y, en estrecha relación con esto, a las diferentes formas en que las religiones fundamentan la validez de las normas y proponen los criterios para la distinción de lo justo y lo injusto, lo bueno y lo malo.

Desde este punto de vista podemos agrupar a las religiones en tres tipos principales. ${ }^{3} \mathrm{El}$ primero comprende las religiones que fundamentan la rectitud de las acciones humanas en su conformidad con un principio superior a los hombres y a los mismos dioses que rige la naturaleza y el devenir de todo lo que existe descrito como rta, tao, asha, diké, etc.

El segundo grupo comprende las religiones que fundamentan la validez de la decisión ética en la obediencia a un mandamiento divino. Lo decisivo en ellas no es el orden, sino el Señor, cuya voluntad lo establece. Él es lo supremo; y la relación con él, la norma que se desgrana en unos mandamientos. Éstos tienen como finalidad introducir al hombre en la esfera de lo divino. Su cumplimiento no hace al hombre tan sólo justo. Lo hace santo, como santo es el Señor de quien proceden los mandatos. ${ }^{4}$

Las religiones de orientación mística en las que el ideal de salvación consiste en la identificación del sujeto con el absoluto, como sucede en el hinduismo de la época de las Upanishads, o en la extinción del sujeto en el nirvana, como sucede en el budismo, los preceptos morales que comporta también el sistema religioso reciben su justificación bajo una forma nueva, la de preparación del sujeto para esos estados en los que consiste la liberación o salvación. ${ }^{5}$ En el hinduismo, los mandamientos éticos tienen la finalidad de disponer al sujeto para esa progresiva interiorización y concentración que culmina en el «tú eres eso» que expresa la "realización» por el sujeto de su identidad con el absoluto. En el budismo, el camino de ocho miembros, término de las cuatro nobles verdades, que comienza con el recto entendimiento y culmina en la recta concentración, está ordenado a la obtención de la iluminación que consuma la extinción del deseo, fuente del sufrimiento, en que consiste el nirvana. La ética es en estas religiones, sobre todo, camino ascético, vía purgativa que prepara para la iluminacion y la union que procura la salvación religiosa.

\section{Contenidos éticos de las diferentes religiones}

Todas las religiones establecen unas prescripciones que regulan la vida de sus adeptos en sus aspectos más importantes.

No es difícil percibir coincidencias fundamentales en la orientación de 
esas prescripciones, aunque los diferentes sistemas religiosos y las diferentes circunstancias histórico-culturales hayan dado lugar a diferencias notables en la determinación concreta de las conductas.

Por una parte, todas las religiones coinciden en prescribir un conjunto de acciones destinadas a encarnar, expresar y comunicar el acto interior de reconocimiento del Misterio que las origina. Son las obligaciones relativas al culto, la oración y a la atención de la comunidad religiosa, sus instituciones y ministros. Pero, por otra, todas las religiones imponen a sus fieles, además de estas obligaciones intrarreligiosas, series más o menos amplias de obligaciones que regulan el conjunto de la vida de sus fieles en aspectos no específicamente religiosos, como son la vida en el mundo y las relaciones sociales.

Todas estas prescripciones se contienen ordinariamente en catálogos de preceptos y prohibiciones presentados como parte de la vida religiosa $\mathrm{e}$ integrados en ella con formas y estilos diferentes. La naturaleza misma de los catálogos difiere notablemente de unas religiones a otras en una amplia gama que va de las religiones que se contentan con ofrecer una orientación global o una inspiración para la vida, como hace el Dammapada budista o el sermón de la montaña cristiano, a las que determinan con toda suerte de detalles los deberes y prohibiciones a que sus fieles deben someterse. Así, por ejemplo, la moral farisaica del judaísmo, de tiempos de Jesús, o la contenida en el Talmud; así también la del zoroastrismo, la de algunas formas de islamismo y determinados desarrollos de la moral católica. Entre estos dos extremos de la casuística moral y de un utopismo poco eficaz se sitúan los catálogos de normas morales en la mayor parte de las religiones. ${ }^{6}$

En cuanto a los contenidos de tales prescripciones, en las religiones existe un capítulo de normas tendentes a capacitar o disponer al hombre para el ejercicio efectivo de la relación con lo divino. Se trata de normas que regulan la relación entre los diferentes niveles de la compleja naturaleza humana y tratan de preservar al hombre del peligro de que determinados aspectos de su vida como lo corporal, lo mundano o las posesiones, le impidan descubrir la presencia de lo divino en su interior, en la vida, en la naturaleza o en la historia. Asi, prácticamente todas las religiones proponen, negativamente, alguna forma de temperancia y todas, positivamente, proclaman el ideal de la prudencia, la sabiduría, la contemplación.

En el campo de las relaciones entre los hombres, las religiones coinciden en regularlas sobre el fundamento de la llamada "regla de orow en su formulación negativa: "No hagas a los demás lo que no quieres que te hagan a ti», o positiva: "Trata a los demás como quieres que te traten a ti». ${ }^{7}$ A partir de esta regla surgen los preceptos, comunes a muchas tradiciones, de no ejercer violencia, no matar, no robar, no mentir. Son muchas las religiones que expresan estos preceptos positivamente, prescri- 
biendo o recomendando la compasión, la ayuda mutua y el amor entre los hombres.

Con frecuencia las religiones regulan la vida de sus adeptos hasta imponerles normas que actualmente situaríamos en el terreno de lo jurídico y legal, pero que en ellas poseen, además, valor moral y religioso. Baste aludir a algunos aspectos de la halakhah judía, la shari'ah islámica y el dharma hindú y budista y a la confusion en determinados estadios de esos diferentes niveles en el seno de la religión. ${ }^{8}$

Como ejemplos clásicos de catálogos de preceptos morales en el seno de diferentes religiones podemos remitir al decálogo judío, el sermón de la montaña, la proclamación de los mandamientos islámicos, las leyes contenidas en el código de Manu para el hinduismo y, en el budismo, los cinco preceptos morales obligatorios para todos, los diez preceptos para los monjes y los desarrollos ulteriores de estos mandamientos hasta llegar a los más de trescientos impuestos a las monjas. ${ }^{9}$

Estos catálogos contienen también normas que regulan la vida social y la vida institucional sobre todo en sus aspectos económicos. Es un rasgo común respetar la propiedad privada, aunque se proponga la comunión de bienes para algunas minorias de selectos, pero todas las religiones insisten en recomendar o imponer la asistencia y la ayuda a los necesitados. ${ }^{10}$

Como resumen de esos contenidos comunes, P. Antes concluye que existen una serie de principios que "constituyen para todas las culturas no cristianas el comportamiento recto del hombre y consiguientemente pueden ser comprendidas en cuanto al contenido como lo que ha sido llamado anteriormente "moralidad natural" que posee también validez ilimitada en el interior de la tradición cristianas." La semejanza de esos contenidos es tal que se ha podido afirmar: "Una de las impresiones más sorprendentes que produce el estudio comparado de las éticas religiosas es la sernejanza en los códigos y enseñanzas morales básicos». ${ }^{12}$

Naturalmente estas semejanzas de base no impiden que el núcleo moral fundamental se desarrolle después en catálogos de preceptos, normas y virtudes peculiares para cada una de las religiones de acuerdo con la propia estructura religiosa y con las culturas en las que se han desarrollado. A la especificación de los preceptos corresponden los consiguientes catálogos de pecados presentes con frecuencia en los rituales previstos para su perdón. ${ }^{13}$

\section{El lugar de la moral en el conjunto del sistema religioso}

Establecida la presencia de la moral en la vida religiosa es necesario, cuando se pretende como nosotros precisar la relación que existe entre ambas, estudiar el lugar que la ética ocupa en la vida religiosa y la relación que mantiene con los otros aspectos de la misma. La historia de las religiones 
ofrece en relación con esta cuestión un testimonio que está muy lejos de ser unánime, al menos en el terreno de las afirmaciones expresas. Así, existen religiones en las que la moral aparece como la consecuencia casi necesaria de la actitud religiosa profunda: el amor del projimo - y la moral del seguimiento en su conjunto- en el cristianismo es considerado por algunos como el impulso -el "no poder ser de otra manera" - que se sigue de la actitud de la fe. ${ }^{14}$ En otras, en cambio, como en el hinduismo y el budismo, la moral parece reducirse a regular las acciones que predisponen para la liberación final que es el término de la actitud religiosa. En unas religiones la moral aparece tan estrechamente vinculada con la vida religiosa que casi se confunde con lo ritual y carece por completo de autonomía; otras religiones - las marcadamente proféticas-, en cambio, oponen lo moral a la práctica de la religión hasta el punto de convertirla en el contenido casi exclusivo de la religión. Hay religiones que hacen de la actitud religiosa la condición y el fundamento único de validez para la acción moral y otras que hacen de la vida moral la señal y el criterio de autenticidad para la actitud religiosa.

Para orientarnos en la clarificación de la cuestión vamos a remitirnos a su planteamiento por la fenomenología de la religión, esa rama de la ciencia de las religiones que se propone precisamente descubrir la estructura del fenómeno religioso y, por tanto, los elementos que lo componen y la ley que rige la relación que mantienen entre sí. Ningún fenomenólogo ha ofrecido una síntesis más clara de la estructura del fenómeno religioso que el más sistemático de todos ellos, J. Wach. En diferentes obras resume esa estructura organizando los elementos de la vida religiosa como un sistema formado por la experiencia religiosa como centro y eje y una serie de expresiones que abarcan a todos los otros aspectos de la religión. La experiencia religiosa es definida en una de las fórmulas más concisas como «la confrontación del hombre con la Realidad esencial». Esta experiencia se expresa y se vive a través del pensamiento, la acción y la comunidad. La segunda categoría de expresiones comprende un doble apartado: el culto, cuyo centro está en la adoración, la plegaria y el sacrificio, y el servicio de la divinidad. "Servicio" debe entenderse en el más amplio sentido del término y se utiliza prácticamente como sinónimo de ética o moral. Las páginas dedicadas por $J$. Wach a este aspecto de las expresiones de la experiencia religiosa abordan muchas de las cuestiones a las que nos hemos referido: la estrecha relación - hasta las religiones de Occidente en la época contemporánea - de la religión y la moral; el origen de la obligación y la normatividad en la «Realidad esencial» y su naturaleza; las distintas formas de concebir ese servicio en las diferentes religiones; las coincidencias y diferencias en los contenidos de las normas y los catálogos de vicios y virtudes en las religiones, etc. Pero más que eso nos interesa aquí la forma concreta de articular el hecho moral en el interior del hecho 
religioso como una expresión junto a otras; creencias, culto, instituciones, de la experiencia religiosa constituida en centro de la religion. ${ }^{\text {is }}$

Es cierto que esta forma de presentar la relación corresponde a un gran número de religiones. Tal vez pueda decirse que a todas en una determinada situación cultural. Pero no faltan indicios, incluso en esas situaciones, de una especie de tensión entre la moral, otros elementos de la religión e incluso el conjunto de todos ellos, que preludia la futura escisión de la moral que forzará a plantear las relaciones en otros términos. Aludamos a algunos de esos indicios, antes de entrar en el análisis de la ruptura entre religión y moral.

Son bien conocidos los enfrentamientos en determinadas religiones, sobre todo las de orientación profética, entre una religiosidad centrada en sus expresiones cúlticas y otra centrada en la acción moral. Testimonios clásicos de esos enfrentamientos aparecen en los profetas de Israel: «Odio, desprecio vuestras fiestas; me disgustan vuestras solemnidades. Me presentáis holocaustos y ofrendas, pero yo no los acepto [...] Haced que el derecho fluya como agua y la justicia como rio inagotable». Pero disponemos también de ecos de este enfrentamiento en otras tradiciones: «Un hombre que no es bueno ¿qué puede tener que hacer con el ritual?» se pregunta Confucio. ${ }^{16}$ De aquí deducen algunos la tendencia, que se observaría de forma cada vez más clara con el progreso de la historia, a una mayor separación de la moral e incluso al establecimiento de su relativa superioridad en relación con la religión. ${ }^{17}$ Esta consecuencia nos parece excesiva porque, sobre todo en los profetas, está claro que la razón de la preferencia de la justicia sobre el culto es la voluntad misma de Dios, es decir, una visión religiosa.

Más claramente aparece la misma tensión en el hecho de que incluso en contextos de una imposición omnímoda de la voluntad de Dios y una determinación absoluta de la moral por ella, aparecen indicios de una especie de constitución de la moral en criterio de discernimiento sobre la autenticidad de la religión, aplicable al mismo Dios. "¿Vas a hacer que perezca el justo por el pecador?" pregunta Abrahán a su Dios. "Quizá haya cincuenta justos en la ciudad. ¿Vas a hacer que perezcan? ¿No perdonarás más bien a la ciudad por los cincuenta justos que hay en ella? ¡Lejos de ti hacer tal cosa! ¡Hacer que mueran justos por pecadores y que el justo y el pecador tengan la misma suerte! ¡Lejos de ti! ¿No va a hacer justicia el juez de toda la tierra? ${ }^{38}$ Idéntica preocupación moral se hace presente en la misma religión de israel y en otros contextos ante el fracaso de la doctrina de la retribución y el cuestionamiento que eso supone para las creencias religiosas. Es verdad que ante ese hecho, determinados textos religiosos reaccionan proponiendo una especie de «suspensión de la moral» y de invitación al creyente a una fe y una sumisión incondicionales y de alguna manera racionalmente "ciegas». ${ }^{19}$ Pero también aquí cabe preguntarse sí el 
significado de esa suspensión es una subordinación completa de la moral a la religión, que termina por suspender la validez de la primera $o$, por el contrario, estamos asistiendo a una purificación de la fe religiosa producida por una quiebra de la moral de la retribución que orienta hacia formas más perfectas de moral en correspondencia con la nueva forma de religión.

Hay en la tradición de Israel un hecho de extraordinaria importancia que, al menos en su tenor literal, parece suponer la subordinación absoluta de la moral a la fe, la reducción de la moral a los mandamientos divinos como su única fuente y la posibilidad de una suspensión de la moral «racional» por un mandamiento positivo de Dios. Es el texto de Gn 22 sobre el sacrificio impuesto por Dios a Abrahán de su hijo Isaac, sacrificio que Dios mismo evitará que se consume. Aparentemente estamos ante una situación en la que la voluntad de Dios impone un acto que repugna a las normas de la moralidad racional y que llevará a Abrahán a tener que transgredirlas para seguir siendo creyente. Así interpretará el episodio Kant tomando pie en él para proponer la subordinación del aparato positivo de las religiones a una religión de la razón que se identifica en la práctica con la moral racional. Frente a una moral basada en la escucha de revelaciones celestiales, el hombre debe basar su conducta en la voz interior del deber moral. ${ }^{20}$

Ahora bien, una lectura detenida de los innumerables intentos de comprensión de este texto enigmático en las tradiciones judía y cristiana permite descubrir que su sentido último no consiste en sustituir una moral racional por una moral basada exclusivamente en unos mandamientos divinos accesibles tan sólo por la revelación, sino en poner de relieve la incondicionalidad de la fe como confianza absoluta en un Dios que termina mostrándose fiel a los principios morales que él mismo ha puesto en la razón.

El formidable comentario a este texto que constituye Temor y temblor de S. Kierkegaard lleva a muchos a leerlo como un caso patente de «suspensión de la moral» y el lugar clásico para fundamentar la prioridad absoluta de la religión como forma de relación con la moral. Parece evidente que Kierkegaard reacciona en esa obra contra la interpretación de Kant y la nueva forma de comprender la relación moral-religión que expresa en ella. Pero es posible que entre las muchas lecturas posibles de un texto escrito evidentemente en clave y que contiene un mensaje secreto-dirigido, tal vez, por encima del lector, a Regina Olsen, la prometida con la que se vio interiormente obligado a romper o a su padre, sujeto de un conflicto moral que pesó mucho sobre la vida de Sören Kierkegaard- deba imponerse la interpretación que subraya ciertamente la incondicionalidad y la superioridad de la fe pero no como actitud que elimina o contradice la moral, sino como principio que permite romper las contradicciones que 
impone a la existencia una norma moral en relación con la cual el hombre siempre se siente distante y en conflicto y de cuyo peso y conflicto es liberado sólo por la fe y la gracia. ${ }^{21}$

Aludamos para terminar esta referencia a las tensiones que la historia de las religiones pone de manifiesto en la relación entre religión y moral, al hecho de que incluso religiones en las que «el reconocimiento de la Realidad última», es decir, la experiencia religiosa, es subrayada como lo "único necesario" para la vida del hombre, cuando ofrecen el resultado último de tal experiencia en esa vida lo expresan en términos que remiten fundamentalmente a una determinada forma de moralidad centrada sobre todo en la justicia, el amor o la compasión, relativizando, en cambio, los actos en los que la relación religiosa se expresa de forma explícita. Con ellos no se produce, ciertamente, la "suspensión de la fe" por la moralidad. Pero sí una impregnación moral de la religión que pone en cuestión una separación excesiva de los dos ámbitos o una reducción completa de la moral a la religión. ${ }^{22}$

Las tensiones aquí aludidas, unidas a otras razones surgidas de determinadas situaciones históricas, van a provocar en algunos momentos de la historia la desarticulación del sistema logrado por las religiones y van a proponer la articulación de la vida humana en torno a otro eje: la razón, la moral o la razón moral.

\section{La secularización de la moral}

Tres son los momentos históricos que suelen proponerse como prototipos - diferentes entre sí- de esa ruptura que resumimos como secularización de la moral: la reforma religiosa de Confucio, el pensamiento griego representado sobre todo por los sofistas y la filosofía moderna a partir de la Ilustración. No podemos pretender ofrecer aquí, ni siquiera en sintesis, la larga y compleja historia de la religión china. Nos contentamos con seña* lar la tendencia a caracterizarla - frente a las religiones proféticas y místicas-como religión sapiencial, y a subrayar la influencia en esta caracterización de la corriente representada por Confucio. De esta corriente se ha afirmado que se opone a la religión centrada en la adivinación, los ritos, el sacrificio y el chamanismo de los primeros períodos (dinastía Shang); continúa la orientación de la dinastía Chou (ca. 1122-221 a.C.) cuyos reyes se propusieron conservar los ritos antiguos en su forma externa pero transformándolos internamente, insistiendo en su contenido moral y buscando así por su medio la educación del pueblo. De esa forma culmina en Confucio un movimiento, ya existente, hacia la constitución de un humanismo racional de contenido sobre todo moral y político, aunque penetrado de una presencia de la trascendencia que le tiñe de ciertos rasgos religiosos. De hecho, la tradición confuciana responde a una situación de crisis pro- 
funda del sistema de los valores, relativizando la ortodoxia y el ritual de la religión antigua y proponiendo una religion racional cuyo contenido es sobre todo ético. Confucio y su escuela ofrecen, pues, "una respuesta moral o ética a la cuestión del sentido de la vida y del orden en la sociedad» $\mathrm{e}$ inician una etapa y una corriente en la religión china que se ha caracterizado como sabiduría ética o "humanización" de la religión tradicional. Se le ha comparado con razón con la filosofía griega clásica y con la filosofía de la época moderna occidental; no pocos de sus rasgos y su orientación general de "doctrina espiritual de sabiduría o de trascendencia de sí pueden acercarla a una especie de "fe moral" o de "religión racional" de estilo kantiano, como ella referida al «cielon, pero más respetuosa del aspecto ritual de la religión. ${ }^{23}$

El segundo momento de ruptura de la integración de la moral en la religión se produce en el pensamiento griego, sobre todo con los sofistas pero, de alguna manera, también con Sócrates, Platón y Aristóteles. En los primeros, las críticas de la religiosidad popular y de su sistema de creencias codificado en los mitos, y su escepticismo en relación con los dioses les conduce a desplazar el criterio y el fundamento de la verdad y del valor de las acciones humanas del mundo de los dioses al del hombre proclamado "medida de todas las cosas». A partir de esas premisas será la sociedad quien deba determinar lo bueno y lo justo y lo hará fundamentalmente por razón de su utilidad.

Platón se sitúa, por una parte, en una perspectiva radicalmente diferente de la de los sofistas. Así, en Las Leyes declara contra Protágoras que "Dios es la medida de todas las cosas en un sentido mucho más alto que en el que ninguno de los hombres pueda, según se dice, esperarse que lo sea alguna vez". ${ }^{24}$ Pero, por otra, critica en la discusión sobre la piedad en Eutifrón la fundamentación de ésta, junto con la de la justicia, en los dioses, lo que ellos hacen o lo que ellos quieren, y defiende como una especie de "ilustrado» que la piedad y la justicia tienen su propia esencia y que como tales son queridas por los dioses. ${ }^{25}$

Estas tendencias ilustradas antiguas se desarrollan plenamente en la Ilustración moderna que tiene en Kant su culmen y prototipo. Desde el punto de vista que nos ocupa su postura puede resumirse en unas pocas afirmaciones que condensan un vuelco radical en la forma de entender la relación entre religión y moral en la tradición religiosa. Kant toma como punto de partida el hecho moral centrado en torno a la buena voluntad caracterizada por «el cumplimiento de su deber por amor al cumplimiento de su deber». Éste se le hace presente al hombre como sobediencia a una ley universalmente válida para todos los seres racionales", representada como imperativo categórico. La validez de ésta no procede de ninguna autoridad externa, ni siquiera divina, ya que la norma sólo tiene validez en la medida en que nuestra naturaleza racional la reconoce como tal. 
«La moral, en cuanto está fundada sobre el concepto del hombre como un ser libre que por el hecho de ser libre se liga él mismo por su Razón a leyes incondicionadas, no necesita ni de la idea de otro ser por encima del hombre para conocer el deber propio ni de otro motivo impulsor que la ley misma para observarlo... Así, pues, la Moral por causa de ella misma no necesita en modo alguno de la Religión, sino que se basta a sí misma en virtud de la Razón pura práctica.»26 Es verdad que la razón práctica presupone como postulado la creencia en Dios como bien supremo capaz de aunar el deber y la felicidad. Pero cesta idea resulta de la Moral y no es la base de ella» y constituye un «teísmo moral», una "fe moral» o una "religión racional», única verdaderamente universal que «impone una cierta normativa apriórica negativa sobre cualquier religión histórica" o revelada y los preceptos que comporta. La moral está, pues, en Kant abierta y orientada a la religión. Pero la religión está definida desde una moral fundada en la razón. Sólo que, si se tienen en cuenta los últimos escritos de Kant, esta razón podría no entenderse como una simple razón humana que "petulantemente se arroga disipar la apariencia mística que encuentra contraria a su dictado»; sino como "una razon humana moral que se ha descubierto en su fondo como portadora de la más genuina mística: la presencia constituyente del mismo Dios». Este hecho, junto con la necesidad humana de la gracia reclamada por Kant permite comprender la filosofía kantiana de la religión, no como la simple construcción racionalista de una religión reducida a moral desde la que se criticaría las religiones positivas, sino como una visión religiosa de la moral que... "hace teónoma la autonomía sin que deje de ser autónoma».27 Tras esta declaración de autonomía de la moral con la consiguiente inversión en la concepción de su relación con la religión, aparecerán, preludiados de alguna manera por autores anteriores como Hume ${ }^{28}$ y Hobbes, filosofías reduccionistas del orden moral que explicarán el mundo de los valores y de las normas éticas desde bases biológicas, psicológicas, sociales o históricas. A partir de estas explicaciones, lo que es vivido como absoluto por el hombre tanto ético como religioso es declarado fruto de la decepción, el resentimiento, la sublimación o la ideologización. Tales explicaciones conducirán en algunos casos a una moral del hombre y sólo del hombre y en otros, al nihilismo. ${ }^{29}$

En todo caso, el desarrollo de un pensamiento, una cultura y una sociedad, que ha tomado conciencia y ha asumido la autonomía de la moral en relación con la religión crea las condiciones para un nuevo planteamiento de sus relaciones con la religión. En efecto, en esa situación se hace plural la misma relación con el más allá de sí mismo antes acaparada por la religión, y se hace posible que algunos sujetos adopten como sentido último la relación con esa trascendencia bajo la forma de una fe filosófica, una fe moral o una fe religiosa: 


\section{La diferencia fenomenologica entre moral y religión. Formas de articulacion}

El punto de partida de ese nuevo planteamiento lo constituye la toma de conciencia de la diferencia fenomenológica vigente entre hecho religioso y hecho moral y entre las actitudes que los originan. Lo esencial de esa diferencia puede resumirse en estos rasgos. ${ }^{30}$

Lo sagrado y lo ético designan dos mundos, dos ámbitos de realidad, en los que el hombre vive su relación con lo último, lo incondicionado, lo supremamente valioso para él. Desde la caracterización general ofrecida al comienzo de nuestro estudio, el mundo religioso se distingue por la mayor "personalizacion" -en un sentido que requeriría de no pocas precisiones- de la relación, el término de la misma y los actos en que se encarna. Así, refiriéndonos a un aspecto fundamental de la diferencia, mientras el contacto con lo incondicional en el mundo ético presenta la forma de un "tú debes" general, en el mundo religioso aparece ligado a un principio personal y requiere del hombre la respuesta igualmente personal de la acogida, la entrega, la fidelidad, la obediencia u otras afines. El mundo de la religión se distingue también por la conciencia de gratuidad y la condición responsiva de todos sus elementos, mientras en el mundo ético predomina el esfucrzo del hombre por ser justo, la justificación activa por parte del sujeto y produce un ascenso del hombre a la altura del Bien. ${ }^{31}$ El conjunto de todos estos rasgos confiere al hombre en cada uno de esos ámbitos un estilo peculiar que origina un tipo de hombre diferente: en el ámbito de lo sagrado, la adoración, la alabanza, el maravillamiento configuran el tipo del santo; en el orden ético, el sentido del deber, la aceptación de la norma constituyen el tipo de hombre justo, honesto, que tiene su posible culminación en el héroe. ${ }^{32}$

Pero la toma de conciencia de la diferencia fenomenológica no puede constituir la última palabra. Como indicábamos más arriba, el hombre, a quien pertenecen estas dimensiones, sujeto único que instaura los diferentes mundos en que vive, necesita organizarlos en torno a un eje que no puede ser más que único, porque sólo puede vivir orientado hacia un norte. Como escribe E. Levinas, necesita dar con «el sentido de los sentidos, la Roma a donde conducen todos los caminos, la sinfonía en la que todos los sentidos llegan a tener voz, el cantar de los cantares». ${ }^{33}$ ¿Cómo lograr esa articulación de los sentidos? Ya hemos visto cómo ha vivido esa articulación el hombre religioso a lo largo de la historia. De nuestra descripción anterior se deducen tres modelos más importantes: el de la religiosidad mística en la que la conducta moral se reduce a predisposición para el ejercicio de la relación religiosa con casos extremos de suspensión de la moral en algunas formas de "quietismo" místico y en algunos "tantrismos» orientales; el de las religiones sapienciales que lo mismo pueden ser 
calificadas de humanismos morales teñidos de religiosidad que de religiones morales; y el de las religiones proféticas que se originan en tomo a una experiencia religiosa fuertemente personalizada de la que extraen unas conductas morales precisas.

La situación de secularización de la moral y la toma de conciencia expresa de las diferencias fenomenológicas de los dos mundos hacen posibles otras formas de articulación. Desde el punto de vista práctico, éstas comprenden formas de religión que ponen su centro en una experiencia del Absoluto fuertemente moralizada, pero mantienen una referencia última a Dios, como garantía última de la vida moral; y comprensiones de la moral en las que la experiencia moral suplanta o sustituye a la experiencia religiosa. Desde el punto de vista teórico caben tipologías de las diferentes formas de artículación de los dos órdenes que, siguiendo a Max Scheler, en relación con la filosofía y la religión, las clasifican en sistemas de identidad total que identifican también formas de relación con lo absoluto y las reducen a una sola; sistemas de exclusión de cualquier relación que definen a cada una de ellas en contraposición con la otra; y sistemas de identidad parcial o xconformidad» que afirman una parcial coincidencia y una diferencia también parcial que permite respetar a cada una de ellas y buscar desde ese respeto la articulación de las mismas. ${ }^{34}$

Desde este marco formal aludamos a algunas de las propuestas de articulación más concretas. La primera mantiene la primacía de la religión y la explica con distintas categorías. J. Wach, por ejemplo, la reconoce en estos términos: "lo sagrado es, más que un cuarto valor que se añada al Bien, la Verdad y la Belleza, la matriz de la que esos valores nacen, su forma y su origen común. Empleando una imagen, la religión no es una rama, sino el tronco del árbol. Por tanto, el análisis de una cultura dada no sólo implica la investigación de las doctrinas teologicas, de los mitos o de los ritos que sirven de medios para descifrar la actitud religiosa, sino que exige que se tome conciencia y se explore la verdadera atmósfera y que se estudien con cuidado las actitudes generales que revela la expresión integral de la vida religiosan. ${ }^{35}$ Desde una consideración que empalma con la reflexión filosófica sobre las propiedades trascendentales del ser se ha intentado mostrar que sacrum constituye un nuevo trascendental, o mejor, la matriz de los demás: unum, verum, bonum, pulchrum: en lo Santo está "por una parte la seriedad del ser personal, no se trata de algo, sino de todo, de mi salvación; por otra parte, la seriedad de intereses por la salvación hace que el yo... se confie a lo que es infinitamente otro de sí mismo". "Lo santo no es un qué envolvente del ser, no es una orientación previa del ser al ente, sino un recuerdo agradecido del ser al origen mismo que otorga... y se oculta en lo otorgado. $m^{36}$

Más conocida es la articulación de los mundos humanos - concebidos en unos lugares como estadios de la vida y en otros como esferas de exis- 
tencia-, por Sören Kierkegaard. La primera de éstas es la esfera o el estadio estético, el de la impresión sensible, en el que el hombre vive en la superficie de su existencia, "cazador de sensaciones que se vuelca sin límites en la inmediatez", encarnado por la figura del Don Juan. El segundo estadio es el ético, tiene su centro en la decisión o la elección: «ese bautismo de la voluntad por la que ésta se incorpora a la ética». En el estado ético el hombre está sujeto al imperativo del deber, de la ley moral, que vale para todos y se sitúa en lo general. Este estadio no es para Kierkegaard el definitivo. «Contra Kant, Kierkegaard propone como cima de la existencia el estadio religioso, cuyo centro es la fe por la que el individuo se refiere a Dios, suspendiendo, como Abraham en el sacrificio de su hijo, la validez universal de la norma moral.» "Kierkegaard invierte, pues, la relacion existente en la moral kantiana entre lo moral y lo religioson, suspendiendo la moral como autosuficiente y abriéndola a Dios como su verdadero fundamento. Para él, "El auténtico absoluto es sólo Dios, ante cuya presencia se realiza el deber moraln, 37

En el mismo tipo de articulación se inscriben los sistemas en los que Dios constituye el único fundamento posible de la moralidad. Los distingo de la propuesta de Kierkegaard, porque se presentan no como descripción de la existencia religiosa, sino como sistemas filosófico-teológicos de explicación de la realidad de los que se deduce la comprensión de lo moral. Los representantes de esta forma de articulación son muy numerosos. ${ }^{38}$ Dostoievski resumía lo fundamental de esta postura en su célebre: \&Si Dios no existe todo está permitidon. Me referiré a W. Pannenberg, como representante de todos ellos, porque él ha tratado de poner en relación esta doctrina con el hecho de la secularización de la moral. Un teólogo español acaba de resumir, en un claro y decidido alegato en favor de la misma tesis, sus afirmaciones fundamentales: afirmada la existencia de verdades universales válidas para todos y establecida como constitutiva la dimensión teologal de la persona, Pannenberg concluye que, sin el reconocimiento público de esa dimensión $\mathrm{y}$, por tanto, de Dios, las normas éticas carecen de fundamento ${ }^{39}$ De estas afirmaciones concluye W. Pannenberg una interpretación de la secularización moderna según la cual ésta constituye una "catástrofe histórica concreta», consecuencia sobre todo de las guerras de religión, y no es el surgimiento filosófico-histórico de un nuevo y superior estado en el proceso de emancipación y autoconstitución del hombre. "Consecuentemente el desmoronamiento de la base religiosa de la moral [...] que esa secularización trae consigo es interpretado como la causa más profunda de la crisis moral de nuestro tiempon, una crisis que tiene su origen en "la crisis de sentido" derivada del alejamiento de la religión, ya que sólo ésta es capaz de ofrecer una interpretación de sentido de la realidad global. De ahí que la única respuesta adecuada a la crisis moral sea una «acertada reteologización de la moralidad", definida como 
"alternativa teocrática», que no significa, por supuesto, una vuelta a la teocracia medieval, porque supone toda una reelaboración de la teología sobre nuevas bases más próximas a la tradición bíblica y cristiana. 40

En la situación de secularización existen, desde luego, otras formas de concebir la vida moral y su relación con la religión. Algunas, siguiendo más o menos de cerca el modelo kantiano ponen la expresión moral como centro en torno al cual articulan la vida, y que no exige ni tolera la referencia a otro fundamento. Recordemos, por ejemplo, la afirmación de $\mathbf{E}$. Weil: «la moral es su propio fundamento, lo es porque depende, como de su razón necesaria, pero también suficiente, de una decisión última (o primera) en relación con la moral, decisión que implica, pues, un acto de fe, procedente de la fe, conducente a la fe», pero a una fe puramente filosofica. ${ }^{41}$

El pensamiento, extraordinariamente fecundo, de E. Levinas constituye el caso más claro de organización del conjunto de la existencia, y consiguientemente, del pensamiento, en torno a la experiencia moral. Para él, en efecto, la última palabra, o la primera, no la tiene el saber como aspiración a la posesión de lo real que culmina en un sistema que nos devuelve la posesión de una totalidad perdida. La experiencia irreductible y última del hombre no radica en "la síntesis, sino en el cara a cara de los humanos [...] en su significación moral». De ahí que exista una prioridad de la experiencia ética ("la filosofía primera es una ética»), en relación con la filosofía y en relación con la llamada religiosa: "La torá oral... saca de la escrita el sentido ético como la última inteligibilidad de lo humanon. Tal comprensión de la experiencia ética, aunque alimentada en las fuentes bíblicas, conduce a una lectura de la religion de Israel que privilegia lo santo sobre lo sagrado y que orienta lo sagrado hacia una santidad concebida en términos éticos que se constituye en criterio y piedra de toque de la religiosidad. Es en la expresión ética donde se produce el verdadero trascendimiento hacia el otro, en el que, tal vez, «la experiencia del cara a cara conduce a Dios», pero ciertamente desde la primacía de la experiencia moral como vía de acceso..$^{42}$

Como muestra de otra forma posible de articulación de las esferas humanas de lo último en la que el centro se sitúa en el pensamiento del ser, aludiré a alguna de las expresiones del pensamiento de Heidegger. Es bien conocida su clara expresión de la diferencia fenomenológica entre el Dios de los filósofos y el Dios de la religión. "Así reza (causa sui) el nombre apropiado para el dios de la filosofía. A este dios no puede el hombre rezar ni ofrecer sacrificios. Ante la causa sui no puede el hombre caer de rodillas por respeto, ni tañer instrumentos, ni danzar,» Por eso el pensamiento sin Dios, que se ve forzado a renunciar al Dios de la filosofía, al Dios como causa sui, resulta acaso mucho más allegado al Dios divino. Se quiere decir aquí sólo: es más libre para él de lo que la onto-teo-logía 
quisiera reconocer ${ }^{43}$ Esta conciencia de la diferencia afecta no sólo a Dios como causa sui, sino también a Dios como valor: sproclamar como última palabra sobre Dios que él es el valor supremo es degradar la esencia de Dioss. ${ }^{44}$ La nueva dimensión en la que según el filosofo hay que plantear la cuestión de Dios es la verdad del ser: «ślo a partir de la verdad del ser puede pensarse la esencia de la divinidad, sólo a partir de la esencia de lo santo puede pensarse la esencia de la divinidad, sólo a partir de la esencia de la divinidad puede pensarse y decirse lo que deba designar la palabra "Dios" $" .45$ Sin entrar en los pormenores de un pensamiento tan complejo, es claro que la clave de la existencia en ella no está en la relación religiosa, ni en la dimensión ética, sino en el pensamiento del ser del que, al mismo tiempo, dice que es "la forma originaria de la poesía». "El pensador dice el ser. El poeta nombra lo santo.» Es decir, que aquí se vislumbra otra posible articulación de la existencia en la que «el posible descubrimiento de la esencia de Dios no sobrepasa la experiencia del ser, sino que se funda expresamente en ellas. 46

\section{Religión y moral en una época secularizada}

La pluralidad de accesos a lo último a que hemos llegado en las sociedades secularizadas, que tiene antecedentes en la historia del pensamiento y de las religiones, origina una situación en la que el problema de las relaciones religión-moral se plantea en términos nuevos. En esta situación resulta difícilmente soluble, desde el punto de vista técnico, el problema de cuál de las dos actividades, la ética o la religiosa, tenga la precedencia sobre la otra. Lo ético y lo religioso, como lo metafísico y lo estético, constituyen más que estadios o aspectos aislables de la vida, dimensiones de la existencia que la afectan en su totalidad, nunca desaparecen del todo de su ejercicio, se enriquecen mutuamente, y que, por eso, se articulan en cada persona de acuerdo con la tradición en que ésta se inscribe, las opciones personales que realiza, sus dotes y cualidades, su talante personal y su formación.

Cada una de estas dimensiones hunde sus raíces en el centro de la persona constituido por la «síntesis de finitud y de infinitud, de lo temporal y lo eterno, de libertad y necesidad" 47 y lo refleja de forma original. Por eso en cada una de ellas se difracta «la luz que ilumina a todo hombre", la presencia originante del Misterio, la religación al poder de lo real, bajo múltiples formas: como conciencia de la contingencia que origina la pregunta "cpor qué existe algo más bien que nada?", como voz de la conciencia, "resonancia de ese fundamento que está agitándose en el seno del espíritu humano ${ }^{48}$ que me dicta qué debo hacer, como impresión de maravillamiento ante el resplandor de lo real como bello; como presencia personal y como llamada que provoca mi invocación y mi adoración. Por 
eso todas las preguntas en las que esas dimensiones afloran a la conciencia remiten en definitiva a la pregunta "¿quién soy yo, hombre?», y todas esas dimensiones revelan la condición humana como habitada por una desproporción o un exceso que hacen que sólo pueda realizarse yendo más allá de sí mismo, trascendiéndose. Las actividades que esas dimensiones generan y que constituyen el hecho moral, la experiencia metafísica, el hecho estético, el fenómeno religioso, son todos ellos, «metáforas para lo último", ${ }^{49}$ difracciones de la presencia siempre elusiva del más allá del hombre, sin la que éste se reduciría a realidad mundana y se deshumanizaria.

De la relación entre estas dimensiones no cabe una explicación que la defina en términos generales sobre la base de una teoría con pretensión de universalidad y necesidad. ${ }^{50}$ Así, la explicación que propone la fundamentación necesaria de la moral en la religión terminaría por no conceder legitimidad en el terreno moral más que a los creyentes de las diferentes religiones -0 , tal vez, si se es consecuente a los de una sola, puesto que en teoría sólo una podría ser verdadera - con lo que los que viven e interpretan su experiencia al margen de las tradiciones religiosas quedarían excluidos de toda legitimidad, o, en el mejor de los casos, tolerados.

Con la secularización del pensamiento y de la conciencia hemos llegado a una situación en la que el hecho moral es vivido en una pluralidad de opciones y experiencias que muestran a la vez la connaturalidad de la experiencia moral y la posibilidad de ser interpretada desde la pluralidad de opciones y tradiciones y con la pluralidad de categorías características de nuestras sociedades pluralistas. El hecho de que todos compartamos una común condición humana explica que a lo largo de la historia, a pesar de la incontable diferencia de códigos concretos de conducta y de explicaciones y motivaciones de la moralidad, se perciba una orientación moral universal que tiene su punto central en el reconocimiento de la dignidad del hombre, el respeto del otro y la puesta en práctica de alguna forma de solidaridad siempre ligada con la búsqueda de la propia felicidad.

Esta coincidencia moral fundamental sigue siendo un hecho en las sociedades altamente diferenciadas y pluralistas de nuestro mundo y constituye un núcleo de convicciones morales compartidas por los diferentes grupos, independientemente de las formas de fundamentación que cada uno propone. Esa coincidencia constituye la llamada ética civil formada por el mínimo moral aceptado por los miembros de una sociedad, un mínimo común que se sítúa más allá de las convenciones sociales, de las normas jurídicas e incluso del marco constitucional aceptado por consenso en las que éstas se inscriben; pero que se sitúa también al margen de las cosmovisiones - dependientes de opciones y convicciones personalespropias de los diferentes grupos sociales.

En este marco la relación religión-moral se convierte en un problema 
emunentemente práctico. ¿Qué puede aportar a la vida moral la experiencia religiosa? ¿Qué puede aportar a la vida religiosa la experiencia ética?

A la primera cuestión nos permite responder la historia de las religiones. La religión ayuda a superar el conflicto que supone la incondicionalidad del deber cuando entra en colisión con la satisfacción de los propios deseos y la propia conveniencia, mediante la promesa de la retribución. ${ }^{51}$ Puede ayudar en la práctica a resolver la antinomia entre el amor de sí y la tendencia a una vida realizada y el respeto al otro y la responsabilidad que origina, mediante la experiencia de la necesidad del trascendimiento para conseguir la salvación, y mediante la vivencia de la relación estrecha entre realización de sí, cuidado o solicitud por él y responsabilidad ante Dios. ${ }^{52}$ Puede también ayudar a superar el conflicto que supone para el sujeto ético la incondicionalidad absoluta del deber y su imposibilidad de cumplirla de forma adecuada. La ética puramente humana, dice en este sentido E. Schillebeeckx - que acepta sin equívocos la autonomía de la moral - exige demasiado a los hombres; es una ética "sin gracia", y para comprender el sentido de la expresión basta comparar la conciencia ética de la culpa, ante la cual el hombre se encuentra prácticamente sin recursos, y la conciencia de pecado, es decir, la experiencia del fracaso moral coram Deo, que abre la posibilidad del arrepentimiento y el perdón. ${ }^{53}$ Por último, H. Bergson mostró una nueva aportación de la religión a la moral al proponer la aspiración mística - como contraste con el fondo generoso de la realidad que hace concabir el proyecto amoroso de la benevolencia universal - como fuente de la moral y religión abiertas. ${ }^{54}$

Pero la misma historia de las religiones muestra que la incardinación de la ética en la religión comporta también peligros que en algunas ocasiones se hacen realidad. Para detectar algunos de ellos bastaría con remitirse a las críticas a las religiones por su tendencia al dogmatismo, al clericalismo, la superstición, la intolerancia, que ha desarrollado el pensamiento moderno y han influido notablemente en la secularización de la moral. Por ello resulta necesario referirse también a las aportaciones de una moral secularizada a las tradiciones morales incardinadas en las religiones. La primera se deriva de la aplicación a la descripción y la fundamentación de la ética de criterios estrictamente racionales, con la consiguiente insistencia en la autonomía característica de la conciencia moral. Es verdad que una razón fínita no puede constituirse en única fuente de racionalidad sin caer en el peligro de ideologización de la razón, que puede terminar en la incapacidad para respetar el carácter incondicionado de la moral, como la propia evolución de la razón moderna ha mostrado. Pero también es verdad que la aplicación de la racionalidad ha eliminado falsas dependencias de tabúes, indebidas autoridades y tradiciones y dogmatismos que han entorpecido el desarrollo de la conciencia moral.

La insistencia de las éticas seculares en el hombre y lo humano como 
criterio y contenido de la moralidad ha desarrollado considerablemente la conciencia de la dignidad del hombre y ha conducido a grupos cada vez más amplios a la toma de conciencia, la estima y el respeto de unos derechos humanos que las tradiciones religiosas no habían explicitado suficientemente, a pesar de contar con principios y razones para ello.

Por último, la extensión de una ética basada sobre principios racionales hace posible la universalización de sus conclusiones, sentando así las bases para el establecimiento de una ética de alcance mundial, aunque sólo pueda ser vivido y expresado en la pluralidad y la variedad de las culturas.

Aceptada la situación de secularización de la moral no sólo como un hecho, sino como marco ideal para el desarrollo de la relación religiónmoralidad, se abre a los sujetos preocupados por el ejercicio de la dimensión moral de su vida tanto desde convicciones religiosas como desde posturas filosóficas humanistas, un cúmulo de tareas. La más importante es, sin duda, mantener un diálogo permanente, desde la base común de la ética civil de nuestras sociedades, para abordar los problemas de la humanidad aplicando los problemas del respeto de la dignidad humana a las situaciones nuevas que originan los progresos científico-técnico y los demás factores de cambio social y extendiendo su aplicación al trato de las masas de poblaciones víctimas del desarrollo de que disfrutamos las sociedades avanzadas.

\section{NOTAS}

1. Sobre los diferentes significados de los dos téminos, cf. A. Cortina, Etica mínima, Madrid, Tecnos, 1956, 23 ss.

2. M. Muller, Leben und Religion, cit. en J. Hessen, Religionsphilosophie, vol. 2, Múnich, E. Reinhard, $1985^{2}, 54$.

3. Desarrollo estos tres tipos en mi estudio "Religión y moral», en M. Vidal (ed.), Conceptos fundamentales de ética teologica, Madrid, Trotta, 1993, 185-203.

4. Martin Buber, Eclip.se de Dios, Buenos Aires, Nueva Visión, 1970, 95.

5. «Monjes, habia dicho el Buda, el fin de esta conducta pura no es ni obtener beneficios materiales, ni obtener la veneración, ni poseer una alta moralidad, ni conseguir la alta concentración. Monjes, el fin último de esta conducta pura es la liberación inconmovible del pensamiento. Esa es la esencia. Ese es el fin.* Cit. en Mohan Wijayaratna, Le moine bouddhiste selon les textes Theravada, Paris, Cerf, 1983, 1.967.

6. J. Wach, El estudio comparado de las religiones, Buenos Aires, Paidós, 1967, 210.

7. Como lugares clásicos en los que se contiene la wregla de oron, cf. Mt 7,22; Lev 19,18; las analectas de Confucio, 12,2; Dammapada, 10,129.

8. Ronald M. Green, Morality and Religion, en M. Eliade (ed), The Encyclopedia of Ret;gion, vol. 10, Nueva York, Macmillan, 1987, 97; cf. también, J. Wach, Sociologie de la religion, Paris, Payot, 1955, 49, donde, citando a Robson afirma que en las sociedades antiguas wla ley [...] era un aspecto de la religión».

9. Ex 20, 20,1-17; Mt 5,1-11; Corán 17,22-39; Codigo de Manu 10,63; M. Wijayaratna, op. cit. $\mathrm{Y}$ del mismo autor, Les montales bouddhistes. Naissance et développement du monachisme feminin, Paris, Cerf, 1991. 
10. R.M. Green, loc, cit, 99.

11. P. Antes, en Ethik in nichtchristlichen Kulturen, Stuttgart, 1984, 11.

12. R.M. Green, loc, cit, 99 . Buenas exposiciones de los contenidos morales de las religiones en Studia Missionalia, 27 (1978); C.H. Ratschow (ed.), Ethik der Religionen. Ein Handbuch: Primitive, Hinduismus, Buddhismus, Islam, Stuttgart, W. Kohlhammer, 1980, Secretariado para los no cristianos, It bene e il male netle religioni, Fossano, Esperienze, s.f. Para la enseñanza moral sobre diversos aspectos de la vida cf. la colección Ethik der Retigionen. Lehre und Leben, Múnich/Gotinga, 1984, con volúmenes dedicados a la sexualidad (1984), el trabajo (1985), la salud (1985), posesion y pobreza (1986). La más completa bibliografía en John Carman y Mark Juergensmeyer, A Bibliography Gutide to the Comparative Study of Ethics, Cambridge, University Press, 1991.

13. J. Martín Velasco, «Dimensión religiosa del pecado», Teologia y' Catequesis (1986), $25-43$.

14. Cf. C.H. Ratschow, Von der Frömmigkeit. Eine Studie aber das Verhältnis von Religion und Ethik, en op. cit., 75.

15. Cf. J. Wach, El estudio comparado de las religiones, op. cit., 185-210. Del mismo autor, Sociologie de la religion, op, cit., $48 \mathrm{ss}$.

16. Am 5,21-24; Is 1,11-17; 58,1-12, etc; Analectas, 3,3.

17. Cf. R.M. Green, loc. cit., $97-98$.

18. Gn 18,23-26.

19. El caso más claro está representado sin duda por el libro de Job y la crisis religiosa que provoca la conciencia de lo cue Job interpreta como una injusticia. Cf. Olegario González de Cardedal, Ética y religion, Madrid, Cristiandad, 1977, 224-225.

20. Cf, por ejemplo, La contienda de las facultades, donde según Kant, Abrahán "tendria que haber respondido a esa presunta voz de Dios, aun cuando descendiese del cielo (visible): "que no debo asesinar a mi hijo, es algo bien seguro, pero que tú, que te me apareces, seas Dios es algo de lo que no estoy nada seguro ni tampoco puedo llegar a estarlo" ", VII, 63, cit. en $\mathbf{J}_{*}$ Gómez Caffarena, "Kant y la filosofía de la religión», en Dulce María Granja Castro (coord.), Kant: de la critica a la filosofía de la religión, Barcelona, Anthropos, 1994, 209; el tema aparece también en $L a$ religión dentro de los limites de ta mera razón (pról. y trad. de F. Martínez Marzoa), Madrid, Alianza, 1969.

21. Para las interpretaciones de Gn 22 en la tradición judía y cristiana y las lecturas de Temor y temblor, remitimos a las excelentes páginas de R.M. Green, en Religion and Moral Reason, Oxford, University Press, 1988, 77-129.

22. Baste remitir, entre otros lugares, a las implicaciones morales y sociales de la alianza y la ley en el judaísmo expuestas en A. Neher, L'essence du prophétisme, París, Presses Universitaires de France, 1955, 156-166; a textos cristianos como Mt 25 y 1 Jn: "quien no ama no conoce a Dios porque Dios es amors; y a pasajes del canon budista como aquel bien conocido cn el que, habiendo descubierto en un monasterio a un monje enfermo que, desahuciado por sus compañeros, yacía cubierto de sus propias inmundicias, el Sakyamuni lo lavó, lo cambio de cama, lo puso sobre su propio lecho y dijo a los monjes: «Oh monjes mendicantes, vosotros no tenéis ya padre ni madre que puedan cuidaros. Si vosotros no os cuidáis unos a otros ¿quién va a hacerlo? Quien quiera preocuparse de mí que se preocupe de los enfemos". Pasaje citado con referencia a los numerosos lugares en que aparece por E. Lamotte, Histoire du Bouddhisme indien, Lovaina, Publications Universitaires, 1958,67.

23. Cf. Julia Ching y Hans Küng, Christianisme et religion chinoise, París, Seuil, 1981, 83-153; también R.M. Green, op. cit., 42-76, quien concluye su exposición afirmando que la historia de la religión en China jlustra el hecho de que "la religion tiene su base en la moralidad, pero no se roduce a cnscñanza moral». Cf. también Etienble, Confucius, Paris, Gallimard, $1966^{2}, 133-139$.

24. Leyes, $715 \mathrm{e} 7-717 \mathrm{a} 3$.

25. Cf. C.H. Ratschow, loc. cit., 21-25.

26. La religión dentro de los limites de la mera razón, op. cit., 19. 
27. Cf. el texto muy esclarecedor de J. Gómez Caffarena, Kant y la filosofía de la religión, cit. supra n. 20 del que tomamos las frases entrecomilladas.

28. Cf. D. Hume, Investigación sobre los principios de la moral, Madrid, Espasa Calpe, 1991, con una interesante introducción de Gerando López Sastre, traductor de la obra.

29. Resumen de estas posturas en M. Buber, Eclipse de Dios, op. cit., 98-101.

30. Para más detalles remitimos a nuestros textos anteriores Introducción a la fenomenologia de la religión, Madrid, Cristiandad, $1993^{5}$ y Religión y moral, op. cit., 197-198 y a los estudios alli citados.

31. Cf J.L.L Aranguren, Etica, Madrid, Revista de Occidente, 19725, 129-176.

32. CE. M. Scheler, El santo, el genio, el heroe, Buenos Aires, Nova, 1961.

33. El humanismo del otro hombre (trad. de Graciano González-Amáiz), Madrid, CaparTós, 1993, 35.

34. Para una exposición más detallada me permito remitir a mi estudio Religión y moral, loc. cit., 191-195; también Introducción a la fenomenología de la religión, op. cit., 191 ss. Dos aportaciones originales aunque no enteramente convincentes a esta problemática la constituyen el intento de R.M. Green en su obra ya citada, por mostrar la existencia de una estructura profunda, presente a todas las religiones y constituida por una «razón moral al mismo tiempo que religiosas que permitirá un nuevo acceso al estudio comparado de las religiones; y la propuesta de $\mathrm{H}$. Ratschow de englobar la ética y la religión en una actitud más alta que él denomina piedad (Frömmigkeit) y hacia la que las dos convergen. Ethik der Religionen, op. cit., 11-77.

35. Sociologie de la religión, op. cit., 19.

36. Cf. L. Hemmerle, P. Hünermann y B. Casper, Besinnung auf das Heilige, Friburgo, Hender, 1965; K. Hemmerle, Lo santo, en Sacramentum mundi, Barcelona, Herder, 1976, vol. VI, 242-249.

37. Cf. José Rubio Carracedo, El hombre y la etica, Barcelona, Anthropos, 1987, 117m125; Eusebi Colomer, Kierkegaard, en el pensamiento alemán de Kant a Heidegger, Barcelona, Herder, 1990, vol. 3, 61-68. De él tomamos las frases entrecomilladas.

38. Cf, entre otros, W. Pannenberg. Antropologia en perspectiva teológica, Salananca, Sígueme, 1993; O. González de Cardedal, Etica y religión, op. cit.; Hans Küng. Proyecto de una ética mundial, Madrid, Trotta, 1991; J.L. Ruiz de la Peña, «La verdad, el bien y el ser. Un pasco por la ćtica, de la mano de la "Veritatis splendor"s, Salmanticensis, 41 (1994), 1-29, con numerosas referencias. Sobre el conjunto de la cuestión, A. Cortina, Ética minima, op. cit., 71 ss.; M. Vidal, Moral fundamental, Madrid, P.S., $1990^{\circ}, 162$ ss. No me refiero aquí a L. Kolakowski y su Si Dios no existe..., ni a M. Horkheimer y su recurso a la teología entendida como unostalgia y anhelo de lo totalmente otro para superar la incapacidad del positivismo para fundar una acción ética, porque sus posturas tienen poco que ver con la de los teólogos aquí aducidos. Para esta cuestión, cf. J. Muguerza, «Un colofón teológico-políticon, en Desde la perplejidad, México / Madrid / Buenos Aires, FCE, 1990, 441-473.

39. J.L. Ruiz de la Peña, art. cit., 11-14.

40. E. Menéndez Ureña, Ética y modemidad, Salamanca, Publicaciones de la Universidad Pontificia, 1984, 76-93. No creo necesario entrar aquí en las razones que me impiden aceptar este último planteamiento, aun cuando reconozca que efectivamente para muchos sujetos religiosos la moral se integra en su vida en una sintesis personal que se orienta en definitiva hacia Dios.

41. Cf. P. Valadier, Mevitable morate, París, Seuil, 1990, 198-199.

42. Para toda la cuestion of. E. Levinas, Ethique et infini, Paris, Fayard, 1982; Totatidade inftnito, Salamanca, Sigueme, 1987; también, E. Schillebeeck, Jesús, como el interrogante htimano sobre Dios: mistica, ética y política, en Jesús en nuestra cultura, Salamanca. Sígueme, 1987, esp. 73-83.

43. Identitat und Differenz, Pfullingen, Günther Neske, 1957,70-71.

44. M. Heidegger, Lettre sur l'htmanisme, Paris, Aubier, 1957.

45. Ibid, 131 .

46. Eusebi Colomer, op. cit., 622. 
47. S. Kierkegaard, La enfermedad montal o de la desesperacion y el pecado, Madrid, Cristiandad, 1964, 47.

48, X. Zubiri, El problema filos 6 fico de la historia de las religiones, Madrid, Alianza / Fundación X. Zubiri, 1993, 69.

49. O «de una cuestión fundamental" en expresión de M. de Certeau para la religion, La faiblesse de croire, Paris, Seuil, 1987, 253.

50. J.L.L. Aranguren, Los valores éticos en la sociedad española actual, Instituto Fe y Secularidad / Fundación F. Ebert, Los valores éticos en la nueva sociedad democrática, Madrid, $1985,13-20$.

51. Cf. R.M. Green, op. cit., 12-16. Aunque habria que subrayar que esa netribución no puede consistir en una compensación externa a la acción moral misma sin peligro de desvirtuar la relación religiosa y la misma acción moral.

52. Cf. E. Schillebeeckx, op, cit., esp. 73 ss.

53. Cf. ibid. También R.M. Green, op. cit, 16 ss.

54. Les deux sources de la morale et de la religión, en Oetwres (ed. del centenario), París, Presses Universitaires de France, 1959, 1.024-1.061. 